\title{
Fatores influentes no processo decisório de agricultores de produtos orgânicos
}

\author{
Nadir Paula da Rosa ${ }^{1}$ \\ Alessandra Juliana Caumo ${ }^{2}$ \\ João Armando Dessimon Machado ${ }^{3}$ \\ Jefferson Andronio Ramundo ${ }^{4}$
}

\section{RESUMO}

A agricultura orgânica vem ganhando melhor visibilidade nos últimos anos, mas na tentativa de acompanhar esse crescimento os agricultores orgânicos, oriundos da agricultura familiar, que atuam nesse sistema de produção enfrentam problemas no processo da tomada de decisão, quanto à produção e aos novos investimentos. O objetivo deste artigo incide em caracterizar os elementos que influenciam os produtores orgânicos à tomada de decisão em suas propriedades e identificar os principais riscos e benefícios inerentes à atividade. Para a realização deste estudo, foram aplicados questionários semiestruturados junto aos produtores orgânicos que participam, aos sábados pela manhã, da Feira da Redenção em Porto Alegre, Rio Grande do Sul. Em síntese, os resultados revelaram que a atividade orgânica, é uma atividade familiar, intensiva em mão de obra, necessitando de muito comprometimento. Constatou-se também que a maioria dos produtores possuem idade elevada, que buscam informações em instituições de assitência técnica, extensão e pesquisa e também por conta própria. $\mathrm{O}$ apoio para desenvolver as atividades vem das associações e da EMATER. Optaram por este sistema de produção pelo incremento de renda, e em razão da qualidade de vida e dos apelos dos consumidores. Em relação aos riscos apresentados na literatura, apenas o risco de preço e mercado foi considerado como menos preocupante pelos agricultores, já que eles relataram que vendem tudo o que produzem sem dificuldade alguma. As estratégias mais importantes, utilizadas pelos agricultores estudados, para a manutenção das famílias e o fortalecimento na geração de renda na agricultura familiar estão atreladas à agregação de valor aos produtos, à diversificação e ao aperfeiçoamento das práticas orgânicas.

Palavras-chave: orgânicos; tomada de decisão; riscos.

\section{The factors that influence the producers of organic in decision making}

\begin{abstract}
The organic agriculture has gained better visibility in recent years, but in an attempt of monitoring this growth the farmers, coming from family farming, whom operate in this production system face problems in the process of decision making, in terms of production and new investments. The objective of this article is to characterize the elements that influence the organic producers to the decision making in their properties and identify the main risks related to the activity. For this study, semi-structured questionnaires were applied to the organic producers who participate, on Saturday mornings, at the "Feira da Redenção" in Porto Alegre, Rio Grande do Sul. In summary, the results revealed that organic agriculture activity is a family activity, labor-intensive, which require a lot of commitment. It was also verified that the majority of the producers are high age, and this producers look for information in institutions of technical assistance, extension and research by own initiative. The support to develop as activities comes from the rural associations and the EMATER (Technical Assistance and Rural

\footnotetext{
${ }^{1}$ Graduação em Administração com Habilitação em Comércio Exterior, Especialização em Comércio Exterior e Mestrado em Agronegócios (CEPAN-UFRGS). Doutoranda em Desenvolvimento Rural pela UFRGS. Docente do Instituto Federal Catarinense (IFC-Videira). E-mail: nadirpr@gmail.com

${ }^{2}$ Graduação em Ciências Econômicas. Mestra em Desenvolvimento Regional e Agronegócio pela Universidade Estadual do Oeste do Paraná, Doutoranda em Desenvolvimento Rural (UFRGS), bolsista CAPES. Professora na Universidade Federal do Maranhão - UFMA, no Centro de Ciências Sociais no Departamento de Economia.

3 Graduação em Medicina Veterinária e Mestrado em Economia Rural (UFRGS). Doutorado em Economia Agroalimentar pela Universidade de Córdoba/Espanha. Professor do Departamento de Economia e Relações Internacionais e Docente Permanente nos PPGs de Desenvolvimento Rural e Agronegócios da UFRGS.

${ }^{4}$ Graduação em Engenharia Agronômica pela Universidade Federal de Viçosa, mestrado em Economia Aplicada pela Universidade Federal de Viçosa e doutorado em Ciências (Economia Aplicada) pela Universidade de São Paulo. Professor associado da Universidade Estadual do Oeste do Paraná.
} 
Extension Company). Producers opted for this production system because there is increasing income, quality of life, and by consumer appeals. In the survey, socioeconomic elements were characterized and discussed how they can interfere in decision-making processes. It is also presented the main risks, considered by organic farmers, related to the activity. It was observed, in the results, that the most important strategies used by farmers to maintain families and the strengthening of income generation in family agriculture are linked to the aggregation of value to products, diversification and improvement of organic practices.

Key-words: orgânic; decision making; risks.

\section{INTRODUÇÃO}

A agricultura orgânica tem desempenhado um papel socioeconômico importante, fazendo com que o produtor rural consiga gerar renda, qualidade de vida e ocupação no campo que envolva todos os membros da família. Apesar das características da agricultura familiar convencional se apresentarem compatíveis com a produção orgânica, reforça-se a necessidade de políticas públicas que visem agregar os interesses comuns dos agricultores e amparar a criação de uma rede de comercialização voltada às especificidades da produção agrícola familiar.

A organização internacional de fomento à produção orgânica é a International Federation of Organic Agriculture Movements (IFOAM), fundada em 1972, na França. A definição adotada pela IFOM para agricultura orgânica é de um sistema de produção que deve promover a saúde dos solos, ecossistemas e pessoas. Com base nos processos ecológicos, biodiversidade e ciclos adaptados às condições locais em alternativa ao uso de insumos com efeitos adversos. Além disso, a agricultura orgânica combina a tradição, inovação e ciência de modo a ser benéfica para o espaço partilhado, promove relacionamentos justos assegurando uma boa qualidade de vida a todos os envolvidos (IFOAM, 2014).

No Brasil, a agricultura orgânica é definida conforme a Lei 10.831 de 23 de dezembro de 2003, em que é caracterizado um processo produtivo onde as condições naturais do meio ambiente são preservadas. Isentando o espaço utilizado das contaminações por produtos sintéticos tanto na produção, como nas demais fases do processo, adotando-se a tecnologia adequada às características culturais e naturais da localidade, resultando na sua sustentabilidade ecológica e econômica.

De acordo com Campanhola e Valarini (2001), a prática da agricultura orgânica propicia vantagens ao agricultor familiar, já que favorece a diversificação produtiva no estabelecimento; requer mais mão de obra, gerando empregos; apresenta menor dependência de insumos externos; elimina o uso de agrotóxicos, contribuindo para reduzir os custos de produção; os produtos orgânicos geram maior valor comercial em relação ao convencional e 
maior vida útil no período pós-colheita. Ainda assim, para Campanhola e Valarini (2001) e Mazzoleni e Oliveira (2010), a agricultura orgânica apresenta alguns desafios como os custos durante o processo de conversão do sistema convencional para o orgânico e os custos de certificação; falta de assistência técnica da rede pública; dificuldades de acesso ao crédito bancário e investimentos em tecnologia; e escassez de pesquisa científica em agricultura orgânica.

Em um sistema de produção orgânica, maiores são as indecisões quanto à adoção de tecnologias que ainda não estão consolidadas, visto que a unidade fica exposta a fatores de riscos. Os riscos estão associados ao manejo que o sistema orgânico requer. $\mathrm{O}$ agricultor deverá implementar várias ações socioambientais e tecnológicas que visem preparar a estrutura para a produção orgânica. Neste tipo de sistema, os riscos muitas vezes estão associados à baixa escala de produção, ao aumento do uso de mão de obra, ao uso de embalagens adequadas para a certificação, aos custos com a certificação, onerando o produto final e também representa um risco de mercado (LIMA, 2005). O autor argumenta ainda que o agricultor deverá adotar algumas estratégias para minimizar os riscos, combinando estratégias de produção e de mercado com intervenção do Estado, entre outras.

Para o desenvolvimento de um sistema agrícola sustentável, sua implementação deve ser de base local e regional. O fortalecimento do poder local, quando precede de uma participação efetiva e democrática das comunidades envolvidas, corrobora com interesses comuns. A aproximação entre produtores, comerciantes e consumidores locais amplia o número de pessoas envolvidas e comprometidas com a proposta de desenvolvimento agrícola sustentável, principalmente ao considerar que o processo de adoção de sistemas agroecológicos de produção não pode ser visto como dependente exclusivamente da decisão do agricultor, devendo o contexto sociopolítico em que o processo ocorre ser levado em consideração.

A capacidade de um indivíduo para tomar decisões pode ser determinada, entre outros fatores, pela sua experiência, maturidade e influência. A tomada de decisão requer um esforço intelectual e de vontade para passar da fase de análise à ação. Decidir é arriscar, é eleger entre alternativas, é encontrar caminhos para a tomada de decisão. Os fatores que influenciam a tomada de decisão podem ser baseados em critérios de acordo com sua racionalidade. Na agricultura, a complexidade a que está exposto o agricultor torna as decisões ainda mais difíceis. O agricultor e sua família, em geral, tomam suas decisões num ambiente de incertezas e riscos, uma vez que os fatores de produção (ambientais e 
econômicos) nem sempre são controláveis. Os recursos econômicos geralmente são escassos e limitados, assim, procura-se um modo de viabilizar os recursos disponíveis na propriedade agrícola e garantir a manutenção e a sobrevivência da família.

Diante disso, o objetivo deste artigo incide em caracterizar os elementos que influenciam os produtores orgânicos à tomada de decisão em suas propriedades e identificar os principais riscos inerentes à atividade. $\mathrm{O}$ interesse para a articulação deste trabalho foi pautado na inserção dos produtores no sistema de produção orgânico pelas redes de articulação e fomento, por meio de organizações específicas, como cooperativas e associações de agricultores familiares.

\section{REFERENCIAL TEÓRICO}

Nesta seção será apresentada uma breve revisão de literatura em relação às abordagens da teoria da decisão bem como de riscos e incertezas na agricultura, também se faz uma síntese da agricultura orgânica e agricultura familiar, estas têm como função fundamentar e auxiliar no entendimento dos achados da pesquisa.

\subsection{O processo de tomada de decisão}

A teoria econômica tradicional pressupõe um "homem econômico", que ao ser economico é também racional. O qual assume ter conhecimento dos aspectos relevantes de seu ambiente, se não completo ao menos imprevisivelmente claro e volumoso. Assume também que este "homem" tem um sistema estável e bem organizado de suas preferências e habilidades que o habilitam a calcular, entre as alternativas que estão disponíveis, e então poderá escolher a alternativa considerada ótima para a organização (SIMON, 1955).

No entanto, essa visão de "homem econômico" declina com a introdução das contribuições de Simon (1957), quando introduz o conceito de satisfação, o qual postulava que as pessoas nem sempre tomam as decisões consideradas economicamente ótimas, mas sim, elas podem priorizar outros objetivos como sociais e intrínsicos.

Simon (1965) destaca ainda que as decisões são mais do que simples proposições factuais, são descrições de um futuro estado de coisas, as quais podem ser verdadeiras ou falsas, em um sentido empírico. As decisões também possuem uma qualidade imperativa, dado que selecionam um cenário futuro em detrimento de outro e orientam o comportamento 
rumo à alternativa escolhida.

Dessa forma, percebe-se a tomada de decisão como um processo complexo, pois dependem da consideração de inúmeras variáveis que influenciam os resultados, sejam elas internas ou externas ao ambiente de decisão. Assim, quanto mais complexo for o ambiente que envolve o processo decisório, mais difícil será a decisão, dado que nem sempre é possível ter algum tipo de previsão (DUTRA, 2008).

Ainda segundo o mesmo autor (p.15), essas complexidades na agricultura surgem em razão de inúmeras variáveis que influenciam a atividade como: "aspectos agronômicos, biotecnológicos, econômicos, ambientais e sociais que estão envolvidos nos processos de produção, distribuição, comercialização e consumo, o que irá demandar, por parte dos seus agentes integrantes, uma visão sistêmica", em razão das inter-relações que existem entre essas áreas do conhecimento e da atuação produtiva. Sendo assim, bem como, asseveram Keshavarz e Karami (2014), quando os recursos (naturais, físicos e financeiros) são escassos, há necessidade de uma avaliação rigorosa de estratégias de enfrentamento para se tomar a decisão mais adequada no atual contexto.

Considerando, que inúmeros fatores influenciam os individuos em seus processos decisórios, cientistas e analistas políticos defendem que as pessoas possuem um conjunto de preferências pré-existentes que consultam durante o processo de fazer julgamentos ou de tomada de decisão. Assim, como as pessoas assumem ter preferências por coisas como alimentos, bebidas, animais de estimação, partidos políticos, também, assumem ter preferências sobre estratégias alternativas para o desenvolvimento econômico, social e ambiental (KELLON; ARVAI, 2011).

Nesse sentido, contribuições de outras áreas do conhecimento, além da economia, auxiliam no entendimento dos processos decisórios, tanto no âmbito empresarial como nas unidades de produção rural. Assim, a participação das ciências sociais contribui para obter análises mais aprofundadas do rural (ANDREATTA, 2009), pois "pessoas estão no centro dos sistemas de produção" (DENT; EDWARDS-JONES; MCGREGOR 1995, p. 339). Por mais que haja vários elementos, de caráter micro e macroambiental, quem de fato é o responsável por tomar a decisão dentro da propriedade e assumi-lá como a mais correta é o agricultor. Para Andreatta (2009), o agricultor é o elemento mais importante da organização de um estabelecimento, é quem coordena o sistema, é o responsável pela tomada, execução e monitoramento das decisões. Segundo os autores Ondersteijn, Giesen, Huirne (2003), essa forte relação entre as características dos agricultores e as decisões tomadas nas unidades de 
produção rural são devido ao fato de que, em muitos países, estas são administradas como empresas familiares, em que o agricultor (e sua família) é ao mesmo tempo empreendedor, gerente e a principal força de trabalho da propriedade.

Diante disto, a maioria dos agricultores encontra dificuldades no processo de tomada de decisão, em razão da amplitude de informações que fundamentam sua decisão. Para Batalha e Souza Filho (2005), o principal problema dos agricultores familiares reside em compreender como ocorre a articulação dos mercados com segmentos pré e pós-porteira, e como funcionam as formas de negociação e práticas de gestão dos processos produtivos.

Ruth Gasson (1973) foi uma das pioneiras em considerar essas premissas para analisar a tomada de decisão dos agricultores. A esse respeito, a autora destaca que os diferentes valores e a maneira que cada agricultor percebe a agricultura, seus respectivos processos de produção e de gestão, são fatores importantes para entender determinadas dinâmicas de uma região ou localidade.

Ondersteijn, Giesen e Huirne (2003) asseveram que as formas de organização dos estabelecimentos, bem como as decisões tomadas, não podem ser entendidas somente a partir dos aspectos técnico-produtivos ou de uma característica específica do agricultor.

Para auxiliar no entendimento da organização do estabelecimento e do porquê das decisões, Chia et al. (2003) consideram três grandes esferas, em maior ou menor grau, interrelacionadas. A primeira esfera considera-se o estabelecimento agrícola a partir de três sistemas em interdependência: i) sistema de produção ou de operações; ii) o sistema de decisão ; e iii) o sistema de informação. A segunda esfera é a das decisões e refere-se à "tradução" que o agricultor faz dos seus objetivos em uma situação dada (caracterizada por potencialidades e condicionantes) e das práticas específicas (pertencentes ao sistema de produção). A última esfera é a sociológica, a qual compreende o ambiente onde o estabelecimento agrícola está inserido; dão sentido a essa esfera a ideia de localidade e comunidade, as relações humanas estabelecidas, as regras, enfim, o conjunto de aspectos culturais e sociais que compreendem esse ambiente.

Ainda segundo Chia et. al. (2003), essas três grandes esferas possibilitam: a) compreender a natureza do sistema de produção, relacionado às ações do agricultor e aos resultados produzidos; b) identificar e compreender como são desenvolvidas as atividades e quais os critérios adotados para a tomada de decisões, em que se explicita particularmente a sua organização e a sua capacidade de regulação, e c) caracterizar o perfil do executor das decisões, assim como as percepções do agricultor, sobre o ambiente no qual ele está inserido. 
Assim, concorda-se com o apontando anteriormente por Simon (1965), Dutra (2008) e Gasson (1973), quer dizer, compreende-se que o processo de tomada de decisão é algo complexo, sobretudo quando se fala de atores que possuem conhecimentos, de certa forma, restritos e informações assimétricas. Nesta perpectiva, na sequência temas como riscos e incertezas serão discorridos, por se tratarem de aspectos muito presentes na agricultura e que influênciam de forma direta na tomada de decisão dos agricultores.

\subsection{Riscos e incertezas}

O risco e a incerteza são básicos para qualquer estrutura de tomada de decisão na agricultura. Riscos podem ser definidos quando o conhecimento é imperfeito, onde a probabilidade dos possíveis resultados é conhecida, e a incerteza existe quando estas probabilidades não são conhecidas. É difícil imaginar um ambiente em que o risco e a incerteza são mais importantes do que no setor agrícola (AIMIN, 2010).

Aimin (2010) explica que as fontes de incerteza e de riscos na agricultura são numerosas e diversas, e que vão desde os eventos relacionados com o clima e as condições meteorológicas, até as doenças dos animais e plantas; oscilações nos preços de produtos agrícolas, nos fertilizantes e outros insumos; incertezas financeiras; riscos regulatórios e políticos. Riscos agrícolas não são independentes, mas estão ligados uns aos outros como parte de um sistema que inclui os instrumentos disponíveis, estratégias e políticas passíveis a gerir o risco

O processo de tomada de decisões é complexo por natureza e essa complexidade se amplia quando inseridos elementos de incertezas e de riscos, como questões climáticas, por exemplo. Para Nelson (1997), esse processo, ao mesmo tempo em que é desafiador, também pode ser frustrante, dado que a decisão, na visão de Nelson (1997), Ondersteijn, Giesen e Huirne (2003), pode estar relacionada a probabilidades subjetivas de grandes magnitudes e a consequências para o futuro.

Ainda nessa perspectiva, Nelson (1997) salienta que a incerteza se refere a uma situação em que as consequências incluem um número de resultados possíveis, independentemente da sua conveniência; e os riscos referem-se à possibilidade de efeitos adversos associados com uma ação. Porém, a eliminação dos riscos pode eliminar também potenciais lucros. A questão é, portanto, que o sucesso está em assumir os riscos certos.

Corroborando com as premissas apresentadas por Nelson (1997), Aimin (2010) 
destaca que a incerteza e o risco ocorrem devido: i) a elementos incontroláveis: como clima, praga de insetos e doenças que desempenham um papel fundamental na produção agrícola; ii) a incertezas e riscos de mercado: as decisões sobre o que e quanto produzir têm que ser feitas com muita antecedência, tendo em vista que o preço de mercado para a produção normalmente não é conhecido no momento em que essas decisões ocorrem. A incerteza do mercado é mais relevante por causa da volatilidade inerente dos mercados agrícolas; iii) ao risco familiar: o qual corresponde a perda de trabalho de membros da família por causa de doença ou acidente, etc.; e por fim iv) a incertezas e riscos políticos: as políticas econômicas têm um impacto em todos os setores por meio de seus efeitos sobre as coisas, tais como impostos, taxas de juros, taxas de câmbio, regulação, provisão de bens públicos e assim por diante (AIMIM, 2010).

Desta forma, compreender a origem e a especificidade de determinados tipos de risco leva a desenvolver uma estratégia de gestão de risco. No caso da produção agrícola, o objetivo da gestão de riscos deve ser o de melhorar ou manter o rendimento de uma exploração agrícola e sua estabilidade financeira e organizacional dentro das etapas tradicionalmente distintas de gestão de riscos (identificação, avaliação e resposta ao risco). Por isso, escolher instrumentos de gestão de risco parece ser de importância fundamental, inclusive, para o público da agricultura familiar de base ecológica, os quais serão apresentados, em maior profundidade, no apartado abaixo (LOMOTT; LYSKAWA, 2014).

\subsection{Agricultura orgânica e agricultura familiar}

A importância da agricultura familiar em termos econômicos, sociais e ambientais está cada vez mais em destaque. Em setembro de 2013, ocorreu o Encontro de Ministros de Agricultura das Américas, no qual foi apresentado o documento "Perspectivas de la agricultura y del desarrollo rural en las Américas: una mirada hacia América Latina y el Caribe 2014”. Este foi desenvolvido pela Comissão Econômica para a América Latina e o Caribe (Cepal), pelo Escritório Regional para a América Latina e o Caribe da Organização das Nações Unidas para a Alimentação e Agricultura (FAO) e pelo Instituto Interamericano de Cooperação para a Agricultura (IICA), (FAO, 2013). O documento destaca que, por meio da agricultura familiar, pode-se aumentar a oferta de alimentos, reduzir as taxas de desemprego, retirar populações mais vulneráveis do meio rural de situação de pobreza e desnutrição. No entanto, são necessários incentivos à inovação, geração de novas tecnologias e promoção de 
sua inclusão nas cadeias de valor. $\mathrm{O}$ documento destaca ainda que a agricultura familiar é de vital importância na produção agrícola, sendo que sua participação no valor agregado agrícola chega a ser superior a $40 \%$. A par disto é que esta seção tem por fim apresentar uma breve contextualização da agricultura familiar no Rio Grande do Sul, bem como a produção orgânica.

Aqui no Brasil, é válido esclarecer que a categoria social da agricultura familiar é caracterizada por legislação, em grande medida, recente. De acordo com a Lei Federal n. ${ }^{\circ}$ 11.326, de 24 de julho de 2006 (BRASIL, 2006), conceitua agricultura familiar como: a) as propriedades que contenham área de até quatro módulos fiscais; b) utilize predominantemente mão de obra familiar nas atividades econômicas do seu estabelecimento ou empreendimento, c) tenha percentual mínimo da renda familiar originada de atividades econômicas do seu estabelecimento ou empreendimento, d) dirija seu estabelecimento ou empreendimento com sua família.

Outrossim, e não menos importante, há que se ter em mente que, conforme aclara Guilhoto et al. (2007), o setor agropecuário familiar é sempre lembrado por sua importância na absorção de emprego e na produção de alimentos, sendo esta especialmente voltada para o autoconsumo, contribuindo mais especificamente com funções de caráter social do que econômicas, considerando sua menor produtividade e menor incorporação tecnológica. Ainda para os autores, contudo, a produção familiar, além de fator redutor do êxodo rural e fonte de recursos para as famílias com menor renda, fato que contribui expressivamente para a geração de riqueza, considerando a economia não só do setor agropecuário, mas do próprio país.

No que tange ao estado do Rio Grande do Sul formado por 496 municípios este apresenta aproximadamente, 378.546 estabelecimentos familiares com uma população ocupada no meio rural de 992.088 habitantes (IBGE, 2006). De acordo com Brumer (2004), o estado do Rio Grande do Sul pode ser dividido em três grandes regiões, com base em sua homogeneidade histórica: a região Sul, que ocupa um pouco mais da metade do território gaúcho, caracterizado pela concentração da posse da terra e, como consequência, pela concentração da renda, por centros urbanos e pela reduzida densidade da população rural; onde predominam a pecuária e, a partir dos anos 1970, as lavouras modernizadas e mecanizadas de arroz, soja e trigo. A segunda região é a Nordeste, constituída pelo eixo Porto Alegre-Caxias do Sul e por algumas áreas no seu entorno. Essa região é a mais industrializada e urbanizada do Estado e em sua agricultura predominam as pequenas propriedades. Por fim, a região Norte, que compreende, grosso modo, a zona de vales e 
planaltos, com cobertura vegetal de matas, sendo fundamentalmente agrária e de pequenas propriedades (BRUMER, 2004).

O meio rural apresenta novos contornos e o produtor rural pode oferecer um espaço para o desenvolvimento de atividades como lazer, turismo, conservação da natureza, residência, prestação de serviços (GRAZIANO DA SILVA, 2002). Dessa forma, a agricultura orgânica entra na nova concepção dos estudos da ruralidade, podendo oferecer aos produtores uma melhoria na qualidade de vida, um local de moradia e de renda monetária. De acordo com Carmo (1998), Fernandes Filho e Campos (2003) e Buainain et al. (2005), as estratégias mais importantes para fortalecer a geração de renda na agricultura familiar estão atreladas à agregação de valor aos produtos e à diversificação. As dificuldades encontradas estão relacionadas com a superação da restrição de escala imposta pela pequena propriedade, influenciando nas decisões dos produtores familiares.

Neste cenário a agricultura orgânica vem ganhando maior visibilidade nos últimos anos, essa prática de agricultura sistematiza uma proposta sustentável composta pelas dimensões econômica, social, ambiental, cultural, política e, ainda, ética. Nesse modelo de produção, caracteriza-se pelo uso de técnicas ecológicas relacionadas à adubação, fertilização, manejo do solo e da produção. Além disso, levam-se em conta os princípios específicos de cada agroecossistema em que as atividades são desenvolvidas. A agricultura orgânica tem por princípio estabelecer os sistemas de produção com base em tecnologias de processos, ou seja, um conjunto de procedimentos que envolvam a planta, o solo e as condições climáticas, produzindo um alimento natural, com suas características e sabor originais, que atenda às expectativas do consumidor.

No sistema de produção orgânica brasileiro, existem basicamente dois tipos de produtores: os agricultores familiares, representando $90 \%$ do total, responsáveis por cerca de $70 \%$ da produção nacional; e os agricultores empresariais que totalizam 10\% dos produtores orgânicos (CAMARGO FILHO et al., 2004). A agricultura orgânica se relaciona com a diversificação do consumo em razão da saturação de produtos convencionais e de novos comportamentos sociais e econômicos (CARMO, 1998). Essa produção na agricultura tende à sustentabilidade, e, fundamentalmente à produção familiar, dada a sua característica de diversificação e de integração de atividades animais e vegetais. Pela pequena escala com que trabalha, a agricultura orgânica pode representar o lócus ideal ao desenvolvimento de uma agricultura ambientalmente sustentável.

No Brasil, a agricultura orgânica começou a ter destaque no cenário nacional a 
partir do início dos anos de 1980, buscando uma atividade rural que fosse ecologicamente equilibrada, economicamente viável e socialmente justa. E, principalmente, uma opção para a inserção dos pequenos agricultores no mercado (CAMPANHOLA; VALARINI, 2001). Para que uma atividade seja considerada orgânica, deve visar: i) à oferta de produtos saudáveis e de elevado valor nutricional, isento de qualquer tipo de contaminação que coloque em risco a saúde do consumidor, do agricultor e do meio ambiente; ii) à preservação e a ampliação da biodiversidade dos ecossistemas, naturais ou transformados; iii) e à conservação das condições físicas, químicas e biológicas do solo, da água e do ar (DAROLT, 2002).

\section{ASPECTOS METODOLÓGICOS}

Para alcançar o objetivo proposto neste trabalho, foram utilizados os seguintes aspectos metodológicos norteadores da pesquisa. Inicialmente, o objeto de estudo e amostra da pesquisa foram definidos. Em seguida disserta-se sobre o instrumento de coleta, variáveis investigadas e análise dos dados.

\subsection{Objeto de estudo e amostra da pesquisa}

A pesquisa de campo foi realizada na Feira Ecológica da Redenção ${ }^{5}$, a qual teve início em 1989, reunindo produtores agrícolas de Porto Alegre e do interior do RS, a qual ocorre todos os sábados pela manhã, na Rua José Bonifácio, 675, em Porto Alegre, estado do Rio Grande do Sul. É organizada pela Secretaria Municipal da Produção, Indústria e Comércio (SMIC). Neste espaço, aproximadamente cinquenta agricultores associados a Associação dos Colonos Ecologistas da Região de Torres - RS/ACERT, Associação de Agroecologia Arco-Íris e a Associação dos Produtores da Rede Agroecológica Metropolitana (RAMA), comercializam seus produtos.

A escolha dessa feira foi realizada em razão de que é a mais antiga feira que

\footnotetext{
${ }^{5}$ Feiras Ecológicas oferecem produtos diretamente dos produtores da área rural de Porto Alegre e do interior do Estado (até $200 \mathrm{~km}$ da Capital) para a comercialização direta ao consumidor. Os hortigranjeiros e alimentos agroindustrializados não têm agrotóxicos, pesticidas e substâncias sintéticas. Os agricultores que trabalham nessas feiras agora estão sendo qualificados também para atender as exigências da legislação sanitária vigente. Os produtos beneficiados precisam seguir as normas do Serviço de Inspeção Municipal de produtos de origem vegetal, o SIM Vegetal. Técnicos do Centro Agrícola Demonstrativo visitam as propriedades prestando o serviço de assessoria para que seus estabelecimentos também estejam de acordo com os critérios de segurança alimentar. As Feiras Ecológicas também estão sendo regulamentadas e em breve os produtos orgânicos de Porto Alegre receberão um selo de origem controlada.

http://www2.portoalegre.rs.gov.br/smic/default.php?p_secao=206
} 
comercializa produtos orgânicos no Estado do Rio Grande do Sul. Foram entrevistados 20 produtores, a seleção dos entrevistados ocorreu a partir do contato direto com os mesmos, no próprio espaço da feira, quando estes foram convidados a participar da pesquisa, de acordo com sua disponibilidade de tempo.

\subsection{Instrumento de coleta e análise dos dados}

Trata-se de uma pesquisa que emprega dois tipos de abordagens, a qualitativa com a apresentação de questões abertas e a quantitativa com questões fechadas. Esta maneira de operacionalizar a pesquisa torna-se importante porque pode salientar os pontos fortes e minimizar os pontos fracos de cada uma (JOHNSON; ONWUEGBUZIE; TURNER, 2007).

A coleta dos dados foi realizada por meio de questionários semiestruturados, aplicado pessoalmente pelas autoras, aos sábados pela manhã, no mês de julho de 2014, a média de duração de cada questionário foi de aproximadamente 40 minutos. O questionário estava dividido em três seções.

A primeira seção continha questões que versavam sobre a caracterização socioeconômica da propriedade: a) número de pessoas residentes em cada domicilio; b) idade, escolaridade dos membros; b) Tamanho da propriedade. Nesta etapa se utilizou para análise dos dados a estatística descritiva, a qual tem como propósito somente resumir, descrever ou apresentar os dados (COLLIS; HUSSEY, 2005) permitindo conhecer de forma detalhada o público em estudo.

A segunda seção referia-se à operacionalização da atividade orgânica como: a) Dificuldades inerentes à atividade; b) Fontes de informações sobre a atividade; c) Instituições de apoio técnico; d) Participação em cooperativas e associações; e) Aspectos referentes à comercialização; f) Principais motivações para inserir-se na atividade. As respostas destas variáveis foram obtidas por meio de questões abertas, e a análise se deu de forma qualitativa, à luz da teoria de tomada de decisão.

E na última seção do questionário foram analisadas as duas questões fechadas, a primeira referente aos benefícios, percebidos pelos agricultores, inerentes a atividade orgânica. A análise se deu por meio de Escala Likert para medir os benefícios na propriedade após o início da produção no sistema orgânico, em relação à: renda familiar, qualidade de vida, qualidade do trabalho, relação familiar e aspecto ambiental, em que foi atribuída uma escala de nota de 0 a 10 ( $0=$ piorou muito e $10=$ melhorou muito). E na segunda questão, foram 
analisados os riscos pelos quais esses produtores passam. Nessa última, também foi utilizada a Escala Likert, para medir o nível de riscos que estes produtores enfrentam em relação ao: risco de preço de mercado, risco de produção, risco institucionais e riscos humanos ou pessoais em que, 0 significa ausência de risco e 10 significa alto risco.

Após a análise dos dados foi realizada uma discussão dos resultados, complementando com outros estudos que apontam como estes elementos influenciam ou não no processo decisório.

\section{APRESENTAÇÃO E DISCUSSÃO DOS RESULTADOS}

Nesta seção, são apresentados e discutidos os dados coletados junto aos agricultores familiares que desenvolvem seus cultivos por meio do sistema orgânico. Sendo assim, apresenta-se, inicialmente, a caracterização dessas famílias para, então, discutir os aspectos mais subjetivos da trajetória orgânica.

\subsection{Caracterização do universo empírico}

Nesta primeira seção apresenta-se a caraterização sócioeconomica das propriedades, bem como a participação dos membros da família em associações e/ou sindicatos, discutindo como esses fatores podem influenciar nos processos de tomada de decisão.

Nas entrevistas realizadas junto aos produtores orgânicos, a composição familiar foi dada em média pela formação de 1 a 4 pessoas no domicílio. De forma detalhada, em 6 famílias, observaram-se 3 pessoas no domicílio, seguida da composição de 4 pessoas em 5 famílias. Apenas o casal, foi a composição encontrada em 4 entrevistados. Em três casos havia apenas o entrevistado e, nos últimos dois entrevistados, havia 6 pessoas na família.

Os entrevistados sinalizaram que há grande participação dos membros da família nas atividades orgânicas, como preparo do solo, plantio das sementes e mudas, cuidados durante o período de desenvolvimento da planta e por fim na colheita e comercialização. $\mathrm{O}$ fator mão de obra familiar é importante nos processos decisórios porque contribui com a redução dos custos de produção, conforme expresso em um estudo desenvolvido por Souza e Garcia (2013) que no sistema orgânico, o item de maior participação nos custos de produção das culturas trabalhadas é o de mão de obra ficando em torno de $38,5 \%$. 
Quando perguntados sobre o tempo dispensado para a execução das atividades no sistema orgânico, $60 \%$ disseram trabalhar os cinco dias da semana e, $40 \%$ trabalham todos os dias, independente de ser feriado ou final de semana. Observa-se, dessa forma, que se trata de uma atividade exigente em mão de obra intensiva, o que exige um comprementimento e gostar do que faz. De acordo com Gasson (1973), agricultores tomam decisões considerando sua satisfação pessoal advinda da prática da atividade.

Observa-se neste sentido que em razão de as famílias serem compostas por um número reduzido de membros podem existir dificuldades na disponibilidade de mão de obra, o que de alguma maneira influencia na decisão dos agricultores em aumentar ou diminuir os investimentos em agricultura orgânica. Como complementação da mão de obra, quando necessário, oito produtores utilizam o contrato temporário e a preferência do contratante é por homens, por ser um trabalho que exige força, mas manifestaram dificuldades de manter a mão de obra empregada. Quando esses produtores necessitam de pessoas para trabalhar sem ser da família, não se consegue contratar por ausência de mão de obra disponível e pelo alto custo, o que demanda capital de giro, geralmente escasso nesse tipo de agricultura.

Quanto à composição dessas famílias, um fato relevante observado no decorrer da pesquisa foi que a idade dos chefes de família é elevada, concentrando-se em torno de 55 a 65 anos de idade em $80 \%$ dos entrevistados. Neste sentido, Reichert e Gomes (2013), salientam que a capacidade de um individuo tomar decisões pode ser influenciada, dentre vários fatores, pela sua experiência, maturidade e influência.

Outro aspecto a ser observado, é, que assim como no sistema convencional de produção, no sistema orgânico também está ocorrendo o envelhecimento das pessoas dispostas a trabalhar nas atividades agrícolas, ficando as propriedades sem perspectivas de sucessão $^{6}$, e então os agricultores baseiam-se na existência ou não de sucessor para a propriedade para fazerem seus investimentos, por exemplo.

No que tange ao nível de escolaridade, ensino fundamental, médio e superior, dos entrevistados inseridos nesse sistema produtivo, foi observado que, dos $80 \%$ com idade elevada, aproximadamente 56\% tem Ensino Superior e os outros 43\% Ensino Médio. Para os demais entrevistados, fora da faixa etária de 55 a 65 anos, os índices foram de $50 \%$ com

\footnotetext{
${ }^{6}$ Para Lobley (2010), a sucessão é o processo de transferência de controle gerencial e de outros ativos intangíveis, como local (fazenda) de conhecimentos específicos. Quando considerada a questão do gerenciamento da propriedade, a sucessão intergeracional representa a renovação da unidade de produção da família e poderá, potencialmente, funcionar como uma correção útil na abordagem da população cada vez mais envelhecida aparente do principal chefe responsável pelo estabelecimento.
} 
Ensino Fundamental anos iniciais incompletos e 50\% com o superior incompleto. Em um estudo desenvolvido por Dalcin (2010), os achados reveleram que pessoas com maior escolaridade tendem a tomar decisões embasadas no custo/benefício e pessoas com menor escolaridade tendem a tomar decisões mais embasadas na intuíção/impulso e na experiência. Para Mazzoleni e Nogueira (2006, p.274), o nível de escolaridade pode ser um ingrediente importante, mas não indispensável, para desencadear o processo de trasnformação. "Produtores com capacitação formal e conhecimento de mercado desempenham um papel de trazer novas visões e quebrar antigos paradigmas, promovendo um efeito de multiplicação das práticas orgânicas".

Quanto ao tamanho das propriedades, aproximadamente 50\% são constituídas por pequenas áreas de terra, pois cerca de 10 delas não possuem mais que uma área total de 10 hectares. Os outros 50\% produtores não ultrapassam os 20 hectares. Dalcin (2010), também encontrou relação entre o tamanho da propriedade e o processo de tomada de decisão. Propriedades com maior tamanho(hectares) tendem a apresentar um processo de tomada de decisão mais ágil e rápido e as decisões tendem a ser mais inovadoras. Propriedades com menor tamanho (hectares) tendem a apresentar um processo de tomada de decisão mais lento e reflexivo e as decisões tendem a ser de natureza mais rotineira.

\subsection{Operacionalização da agricultura orgânica}

Nesta segunda seção, apresentam-se como ocorre o desenvolvimento da atividade orgânica, processos de produção, fontes de informações sobre a atividade, apoio técnico, comercialização, motivações para inserir-se na atividade e por fim os principais beneficios percebidos.

Além das dificuldades inerentes a atividade agrícola, como adversidades climáticas e biológicas, por exemplo, na agricultura orgânica também se enfrenta dificuldades com as práticas de manejo que os vizinhos empreendem em suas propriedades de agricultura convencional. Neste sentido, os produtores orgânicos relataram à negligência e o desrespeito por eles enfrentados, em relação ao manejo da produção agrícola realizada por seus vizinhos, com produção convencional, em especial quando da aplicação dos herbicidas, fato que afeta diretamente a produção de base orgânica. Isso, de certa maneira, foi constatado nas falas de aproximadamente $40 \%$ dos entrevistados, que alegam sofrer pressão discriminatória por produzirem com base no sistema orgânico. Outrossim, tal situação, muitas 
vezes, inviabiliza não só a produção dos interlocutores, interfirindo no equilíbrio do agroecossistema, como também reduzem a possibilidade de ganhos econômicos, pois produtos sem a comprovação da qualidade orgânica são comercializados em mercados convencionais.

Como todo começo prediz informações, destaca-se que iniciar uma nova atividade, inclusive orgânica, demanda conhecimento e relatos de experiência, para, então, decidir inserir-se ou não na atividade. Neste interim, os dados do estudo retratam que os agricultores que trabalham com sistemas orgânicos adquiriram seus conhecimentos para iniciar na atividade por iniciativa própria, ou seja, 50\% dos entrevistados destacaram ler e buscar informações sobre o assunto, 25\% destacaram que a Empresa de ltência Técnica e Extensão Rural- Emater, foi quem transmitiu essas novas tecnologias de produção, $20 \%$ foram os que se interessaram pelo sistema e então procuraram outras associações que já atuavam, 20 \% creditaram à Universidade Federal do Rio Grande do Sul (UFRGS), os conhecimentos que possuem sobre o sistema orgânico.

Em outros casos, porém menos expressivos, o conhecimento foi absorvido a partir da participação de encontros de formação, grupos de jovens, formação na Igreja Católica e cursos de formação do Centro Ecológico. Esse mesmo cenário foi apontando pelos autores Assis e Romeiro (2002), os quais destacam que a difusão do sistema de produção orgânica ocorreu inicialmente baseada em iniciativas dos próprios produtores, aqueles que já tinham algumas convicções ideológicas.

Nesse sentido, observa-se que ainda há uma lacuna para propagar a agricultura orgânica e que a adesão ao sistema depende da vontade de cada agricultor em buscar informações, sobre a atividade. As políticas públicas, que seriam as agentes de fomento, apesar de existirem ainda são poucas necessitando de ajustes e investimentos.

Já Rozman et al. (2013), em um estudo sobre prospecções de cenários para o desenvolvimento na agricultura orgânica, destacam que os impulsos para a conversão da agricultura convencional para a base orgânica está baseada em subsídios. No entanto, os autores acrescentam que os subsídios não são a única força que impulsiona o sistema, ainda mais salientes são as atividades que promovam a agricultura orgânica. E que as políticas para encourajar a produção orgânica devem se concentrar em atitudes, tecnologias e finanças. Sendo assim, a adoção de tais estratégias poderá impulsionar mais seguidores a inserirem-se na atividade.

Dentre as instituições que exercem papel significativo junto aos produtores, citou- 
se a Emater, tanto que entre os entrevistados, $60 \%$ destacaram que tal instituição oferece constantemente cursos de aperfeiçoamento, bem como assistência técnica aos agricultores. Outra entidade citada por $50 \%$ dos entrevistados como fomentadora de cursos de formação foi a Rede ECOVIDA (rede de certificação participativa). E, 30\% dos agricultores, destacaram que, além das instituições anteriores, buscam aperfeiçoamento no SENAR, Centro Ecológico e outras instituições que ofereçam cursos na área.

Ainda em relação à informação, como formas de apreensão dos conhecimentos, $20 \%$ dos respondentes citaram a metodologia de Dias de Campo com contato com outros produtores, em que os agricultores observam como as novas experiências vêm sendo aplicadas por colegas agricultores, bem como ouvem os relatos de erros e acertos. Contato com outros agricultores, como forma de obter informações e conhecimento, também foi citado por Oliveira (2007), onde os resultados revelaram que os contatos com outros produtores é a segunda melhor fonte de informação. Assim, destaca-se que as fontes de informações bem como a forma de apreendê-las influenciam nos processos de decisão, como pode ser observar em Machado (1999), que pesquisando agricultores de culturas irrigadas na Espanha, constatou que o acesso e a qualidade da informação são fatores influentes no processo decisório.

Quanto ao apoio técnico, tanto para produção quanto para a comercialização, a EMATER oferece apoio intensivo, haja vista que $75 \%$ dos agricultores destacaram ter a entidade como suporte técnico. A rede ECOVIDA, a SIC de Porto Alegre e outras associações auxiliam em torno de $30 \%$ e $20 \%$, respectivamente. Dalcin (2010) investigou ainda a relação entre assistência técnica e tomada de decisão. Os resultados revelaram que os agricultores que possuem assistência técnica, tendem a tomar decisões mais embasadas no custo/ benefício, e apresentar um processo de tomada de decisão mais lento e reflexivo.

$\mathrm{Na}$ construção da estratégia de desenvolvimento rural $^{7}$, a organização, em cooperativas, associações dentre outros, dos produtores familiares é apontada como um instrumento fundamental para sua viabilização de produção. Outrossim, a participação dos agricultores familiares em organizações ou redes promove alternativas de canais de comercialização e trocas de informações e experiências. Nessa perspectiva, todos os

\footnotetext{
${ }^{7} \mathrm{O}$ desenvolvimento rural é definido como um processo que resulta das ações articuladas, que visam induzir mudanças socioeconômicas e ambientais no espaço rural para melhorar a renda, a qualidade de vida e o bemestar das populações rurais. Dadas as especificidades e particularidades do espaço rural, determinadas pelos condicionantes sociais, econômicos, edafo-climáticos e tecnológicos, o desenvolvimento rural refere-se a um processo evolutivo, interativo e hierárquico quanto aos seus resultados, manifestando-se nos termos dessa complexidade no plano territorial (SCHNEIDER, 2004, p. 98)
} 
agricultores que compõem o estudo participam das associações da sua cidade e, 10, do Sindicato Rural, ressaltando que, no caso das associações, elas facilitam para que os produtores obtenham melhores resultados e acesso às informações de venda, manejo, cultivo, entre outros atributos.

No tocante à comercialização, as vendas na feira, que ocorrem semanalmente, correspondem a mais de $70 \%$ da produção total realizada. Foi observado pela maioria dos entrevistados que o mercado atualmente está aquecido e que, muitas vezes, faltam produtos para a demanda existente. Além da feira, foram levantados outros pontos de venda do qual eles participam. Quatro produtores vendem em mercados, outros quatro em restaurantes e quatro produtores participam do Programa Nacional de Alimentação Escolar (PNAE) e 10 do Programa de Aquisição de Alimentos (PAA), do Governo Federal, o que possibilita venda garantida por um ano. Neste sentido, a garantia de venda e prospecção de um mercado aquecido influencia os agricultores a tomarem suas decisões, seja ele em função de ampliação ou diminuição de quantidade produzida.

Quanto ao aquecimento do mercado de orgânicos Campanhola e Valarini (2001), destacam que existem cinco razões para o aumento da demanda por produtos orgânicos. $\mathrm{O}$ primeiro argumento está relacionado à preocupação dos consumidores com a saúde e à importância da alimentação saudável. O segundo foi caracterizado pela influência do movimento ambientalista organizado por meio de ONGs que criam espaços e incentivam a produção e o consumo. Em terceiro, observa-se a influência de seitas religiosas que defendem o equilíbrio espiritual do homem, por meio da ingestão de alimentos saudáveis e produzidos em harmonia com a natureza. O penúltimo argumento está na importância das ações executadas por grupos organizados contra a moderna agricultura. E em último, a utilização das ferramentas de "marketing", pelas grandes redes de supermercados, por influência dos países desenvolvidos, que teriam induzido demandas por produtos orgânicos em determinados grupos de consumidores".

Dentre os produtos vendidos nesses pontos de venda, cerca de $70 \%$ são de verduras, folhas e tubérculos em geral. Ainda compõe o portfólio de vendas, as frutas in natura e processadas, somando $40 \%$, sendo que a produção processada compreende as geleias e sucos, pães e bolos, queijos, derivados do mel, cereais e produtos da cana-de-açúcar. Singha, Dorwarda e Osbahr (2016) em seu estudo desenvolvido na India, encontraram que os pequenos agricultores empreenderam como estratégias para amenizar os riscos, modificação das práticas agrícolas e a diversificação das culturas. 
Dentre as mais diversas motivações que levaram os agricultores a produzir de forma orgânica, $40 \%$ disseram que essa forma de produzir vem de família, que seus pais já haviam aderido ao sistema e que eles, ao fazerem a opção por uma atividade, preferiram se manter no mesmo sistema em que acreditam. Essa informação vai ao encontro das afirmações de Simon (1965), segundo o qual, no processo de decisão, os indivíduos definem suas escolhas influenciados, em maior ou menor grau, por crenças, valores, atitudes e que, considerando as limitações da natureza humana e das organizações, a melhor alternativa do modelo racional deve ser substituída pela alternativa mais satisfatória.

Para $30 \%$ dos respondentes, a motivação vem do incremento de renda que a atividade proporciona. Também dentre os agricultores entrevistados, 20\% destacaram trabalhar anteriormente com o sistema convencional e, por problemas de saúde em razão da aplicação de agrotóxicos, também optaram por inserir-se na atividade orgânica. Outros 10\% dizem que os consumidores estão cada vez mais exigentes, querem consumir mais produtos saudáveis e estão pagando mais por isso. Eles também possuem uma preocupação com o meio ambiente.

Motivação econômica já era citada, como fator influenciador nos processos decisórios, pela teoria neoclássica. Já Gasson (1973), defende que além das motivações econômicas agricultores decidem baseados em um conjunto de valores e de como eles percebem a agricultura. Somando-se a isso o comportamento do consumidor também é um fator influenciador no momento da decisão, conforme explanado por Blackweell, Miniard e Engel (2005), o comportamento do consumidor é uma ciência que tem influência de várias áreas do conhecimento como da Economia, Psicologia, Antropologia e outras disciplinas. Esses aportes servem de suporte para o conhecimento de cultura, valores, crenças e desejos, tudo o que influencia no processo de decisão de compra, por exemplo.

Em síntese, observou-se no estudo que a atividade orgânica, é uma atividade familiar, intensiva em mão de obra, necessita de muito comprometimento. Constatou-se também que a maioria dos produtores possuem idade elevada, que buscam informações em instituições de assitência técnica, extensão e pesquisa e também por conta própria. $\mathrm{O}$ apoio para desenvolver as atividades vem das associações e da EMATER, optaram por este sistema de produção pelo incremento de renda, em razão da saúde e dos apelos dos consumidores. E o mercado de orgânicos encontra-se aquecido. 


\subsection{BENEFICIOS E RISCOS PERCEBIDOS PELOS AGRICULTORES}

Nesta seção dois aspectos referentes à atividade orgânica são apresentados. Os beneficios e os riscos percebidos pelos agricultores em relação à atividade.

Para a constatação de que algo pode ter melhorado na propriedade, ou mesmo na relação familiar, após o início da produção de base orgânica, na Figura 1, foi utilizada a Escala Likert ${ }^{8}$. Atribuem-se notas de 0 a 10 , em que 0 indica que piorou muito e 10 melhorou muito, para os atributos de renda familiar, qualidade de vida, qualidade do trabalho, a relação familiar e o aspecto ambiental, segundo a percepção do informante.

Figura 1- Atributos da produção orgânica.

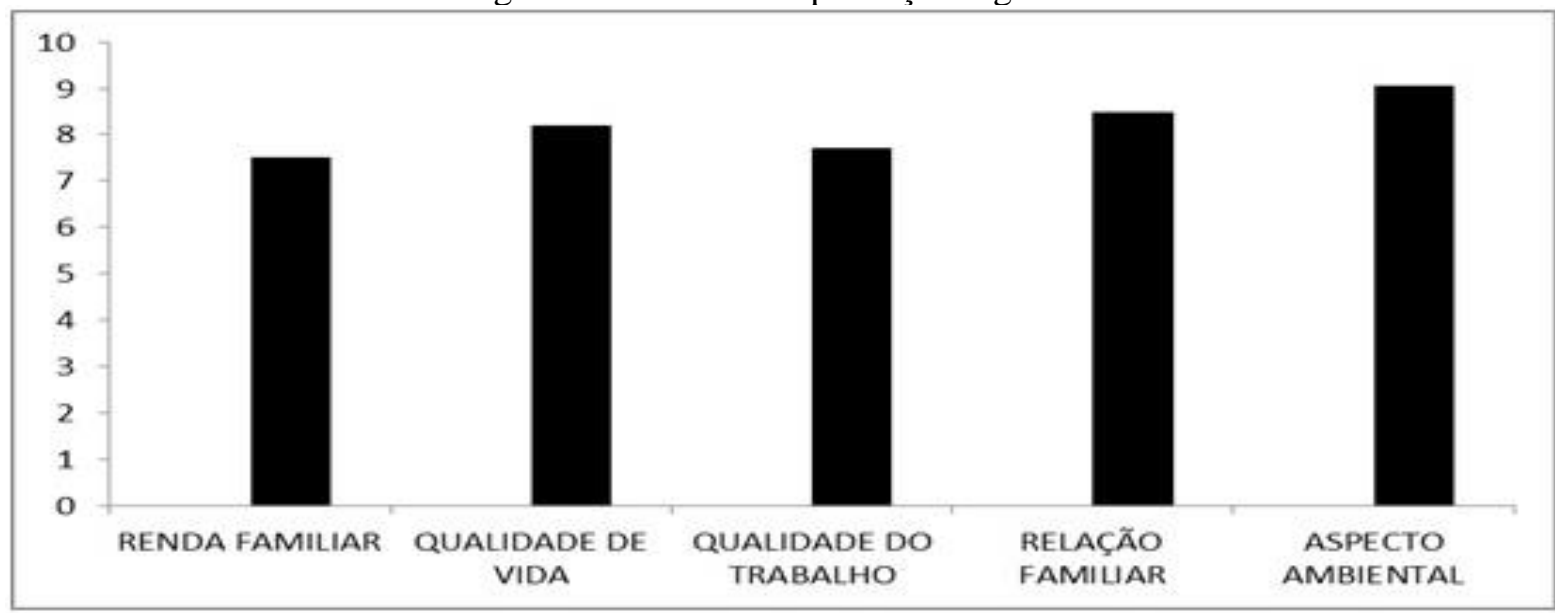

Pesquisa de campo (2014).

No atributo da renda familiar, em relação a melhora depois de ingressar no sistema orgânicos, o que mais foi observado nas respostas é que não houve diferenças significativas pelo fato de se aderir a esse sistema de produção. Pequenas diferenças na retabilidade da produção de hortaliças orgânicas quando comparadas as convencionais também foi encontrado no estudo de Souza e Garcia (2013).

A motivação em produzir no sistema orgânico surge em razão de os agricultores acreditarem ser a melhor escolha quanto aos benefícios em relação a saúde e a qualidade de vida e do meio ambinte. Como ressaltado por Gliessman (2005, p.590), "a perspectiva agroecológica é mais do que somente a ecologia aplicada à agricultura. Ela precisa assumir uma perspectiva cultural, à medida que se amplia no sentido de incluir os seres humanos e seus impactos sobre ambientes agrícolas".

\footnotetext{
${ }^{8}$ Além da Escala Likert para fazer a Figura 1 foi feito a média das repostas para cada atributo dos 20 produtores, o que também foi considerado para a confecção da Figura 2.
} 
Na relação familiar, foi ressaltado que a interação entre os filhos melhorou, pela intensificação da participação de todos em alguma atividade relacionada a agricultura orgânica. Fato que poderá envolve-los e motivá-los a investir e permanecerem na atividade.

Já o aspecto que apresentou a pior atribuição foi o que envolve a qualidade do trabalho. Isto se deve ao maior dispêndio laboral dos membros da família, pois a atividade é intensiva em mão de obra, obtendo uma média em torno de 7,7, sendo um fator relevante, já que alguns dos produtores estão envolvidos, no processo de produção bem como no processamento da produção, todos os dias da semana. Esse fator pode ser crucial no momento da decisão em investir na atividade e decidir torna-la a principal fonte de renda ou mesmo optar por desistir atividade.

Aspecto este que foi investigado por Barth et al. (2016) junto aos agricultores do município de Linha Nova, localizada na região serrana no interior do Rio Grande do Sul, os achados revelaram que os mais jovens não querem mais atuar em atividades pesadas, "trabalho judiado" como eles denominam, estas expressões são utilizadas para justificar a não permanência dos filhos dos agricultores no empreendimento da família, os quais fazem menção principalmente aos aspectos negativos do trabalho.

A melhor atribuição, em média, foi o aspecto ambiental, com nota 9, observado, principalmente, por cerca de $80 \%$ dos entrevistados, por estarem já há 15 ou mais de 20 anos no sistema produtivo orgânico. Assim, Mzoughi (2014) observa em seu estudo que os agricultores buscam no sistema produtivo orgânico bem estar, qualidade de vida, felicidade, saúde, reconhecimento social satisfação no trabalho e lucratividade. Na amostra, foram verificados também os principais riscos que podem afetar a produção orgãnica. Utilizou-se uma escala likert, em que 0 não apresenta risco e 10 o risco é elevado (Figura 2).

Figura 2. Disposição para assumir riscos

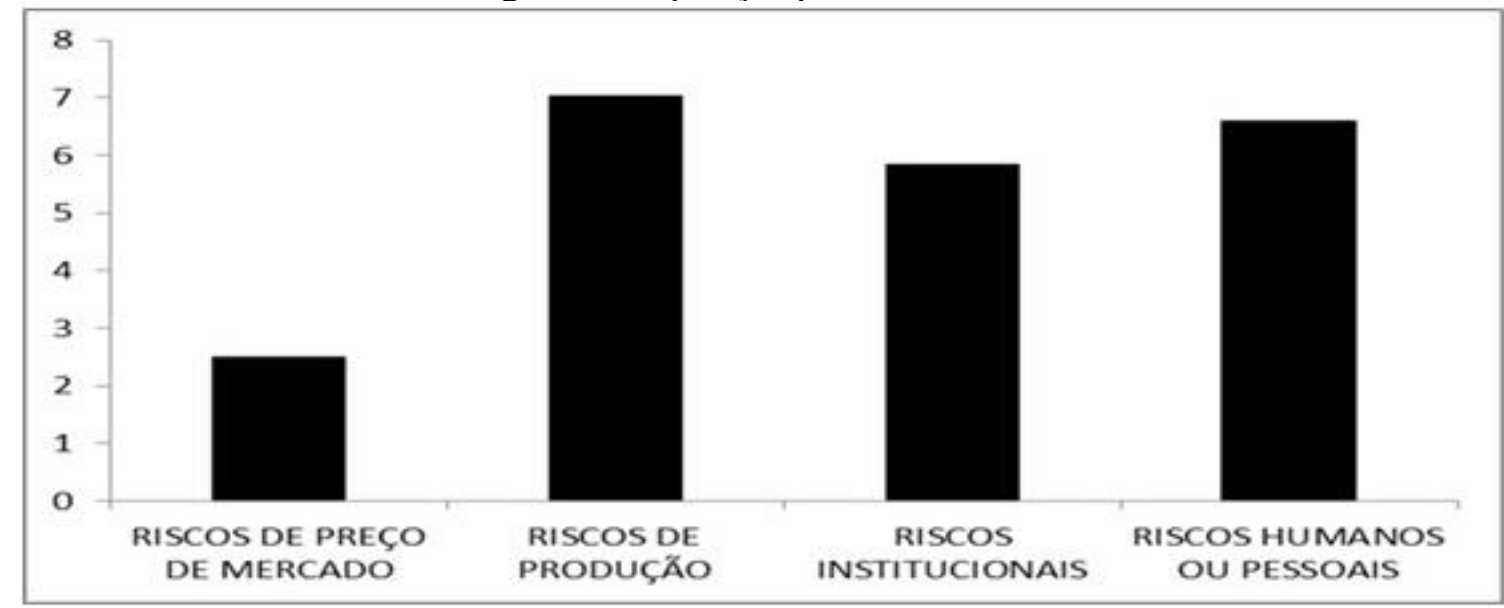

Fonte: Dados da pesquisa (2014) 
Ao analisar os desafios relacionados à produção e à comercialização dos produtos de base orgânica, os riscos e as incertezas estão presentes em todas as etapas do processo para os produtores. Contudo, o que apresentou menor risco para sua produção e comercialização foi o preço de mercado, com uma média de 2,5, evidenciando o argumento de que o mercado orgânico está crescendo e que sua demanda está extrapolando a sua oferta. Este resultado mostrou-se oposto aos apresentados por Nelson (1997) e Aimim (2010) para o setor agrícola, os quais destacam o preço e o mercado como principais riscos do sistema agrícola. No entanto, os demais riscos apresentados e considerados pelos entrevistados, são compartilhados por Nelson (1997) e Aimim (2010).

Por exemplo, para o risco de produção, o valor foi de sete, já que esses produtores ainda dependem de uma ampliação de suas estruturas de produção bem como de maior disponibilidade de informações sobre a tecnologia, e ficam muito expostos aos fatores climáticos, como o excesso de chuva ou, ainda, altas temperaturas e secas em períodos de estiagem.

Os riscos intitucionais foram a segunda média com menor nota atribuída pelos produtores, em torno de 5,5, sendo justificada que nos últimos anos a produção familiar e orgânicaforam incentivadas e os meios de comunicação os ajudaram na divulgação dos produtos. Porém, ainda existe uma uma lacuna em relação aos aspectos burocráticos, no acesso aos programas de crédito, como no caso do PRONAF, que poderia ajudá-los na na estruturação dos seus sistemas produtivos, por meio de aquisição de máquinas para o processamento dos produtos, equipamentos de irrigação, material para confecção de estufas, telas para amenização das altas ou baixas temperaturas para a produção de verduras e hortaliças, equipamentos para cozinha no preparo de pães, bolos, geleias e sucos e garantias de comercialização. De acordo com Petrelli e Silva (2004), o PRONAF previligia a propriedade familias "eficiente" em deterimento dos mais fragilizados. Sendo que grande parte das liberações se dá por meio da modalidade de crédito rotativo, o qual é acessível apenas aos produtores que já tem cadastro nos bancos e que estão ligados a produção de produtos de alto grau de integração.

Outro fator citado é a troca dos responsáveis administrativos públicos, como no caso de governadores e de presidente. Fato que denota a descontinuidade de programas implantados ou objetivos de governo e que nos casos de o agricultor ter feito algum investimento baseado nesta perspectiva acaba perdendo tempo, dinheiro e ainda se desmotiva em relação a atividade. 
Por fim, os riscos humanos ou pessoais ainda pesam em relação à necessidade de contratação de mão de obra, observada pela escassez de pessoas para trabalhar e a especialização, ou ainda, a burocracia que envolve a contratação para pequenos produtores.

Para finalizar, apreende-se que parcela significativa dos interlocutores operam em um contexto arriscado e incerto. Além da variabilidade e mudanças climáticas, as dinâmicas sociais, ambientais, institucionais e relacionadas ao mercado afetam suas decisões e capacidade de enfrentar e adaptar-se as situações encontradas (SINGHA; DORWARDA; OSBAHR, 2016).

\section{CONSIDERAÇÕES FINAIS}

Tendo por intuito atender ao objetivo deste artigo, o qual incide em caracterizar os elementos que influenciam os produtores orgânicos à tomada de decisão em suas propriedades e identificar os principais riscos inerentes à atividade é que apresentaremos as considerações finais do estudo.

Observou-se que trata de uma atividade de cunho familiar, e necessita de mão de obra intensa. Os resultados revelaram que as famílias e as áreas das propriedades são pequenas, ou seja, com poucos membros e poucos hectares por estabelecimento, e o chefe da família possui idade elevada, aspectos estes que podem influenciar na decisão de investir, em razão de que a propriedade poderá não ter sucessor definido.

A busca por informações parte em sua maioria, do produtor, tendo como instituições de suporte para fornecer informações, desde o processo de produção até a comercialização as instituições Emater, ECOVIDA, SENAR e UFRGS, dentre outras em menor proporção.

Foi observado também, que a produção de base orgânica preserva as características da agricultura familiar, reforçando a necessidade de políticas públicas que visem agregar os interesses comuns dos agricultores e amparar seu acesso ao PRONAF, facilitando a produção, em longo prazo, com amenização dos riscos envolvidos na produção por fatores externos, como climáticos e de comercialização, por exemplo, bem como voltadas às especificidades da produção agrícola familiar.

Quanto aos quesitos que melhoraram com a atividade orgânica, um dado surpreende: a renda não é o principal fator motivador para os agricultores estarem nesse sistema, mas sim qualidade de vida, saúde, relação com a família e com o meio ambiente. 
Ao analisar os principais riscos ou mesmo os principais desafios relacionados à produção e à comercialização dos produtos de base orgânica, buscaram-se evidenciar os problemas que afetam os agricultores familiares, bem como as contradições encontradas neste processo. O que se pode destacar é que o mercado para esses produtos se encontra em expansão, com uma demanda aquecida e ainda com oferta restrita.

Observou-se que dos riscos apresentados na literatura pelos autores Nelson (1997) e Aimim (2010), apenas o risco de preço e mercado foi considerado como menos preocupante pelos agricultores, já que eles relataram que vendem tudo o que produzem sem dificuldade alguma.

Por fim, este trabalho apresentou e caracterizou os principais elementos presentes na atividade orgânica e que em maior ou menor grau podem influenciar nos processos de tomada de decisão por parte dos agricultores. Também evidenciou os principais riscos inerentes a atividade. Tendo em vista, estas considerações percebem-se que é uma atividade que necessita de muitos investimentos, tanto no suporte econômico para investimento como no suporte de assistência técnica e de comercialização.

\section{REFERÊNCIAS}

AIMIN H. Uncertainty, Risk Aversion and Risk Management in Agriculture. Agriculture and Agricultural Science Procedia, Amsterdam, n. 1, p. 152-156, 2010.

ANDREATTA, T. Bovinocultura de Corte no Rio Grande do Sul: um estudo a partir do perfil dos pecuaristas e organização dos estabelecimentos agrícolas. 2009. $241 \mathrm{fls}$. Tese (doutorado em desenvolvimento rural) Programa de Pós-Graduação em Desenvolvimento Rural. Universidade Federal do Rio Grande do Sul, Porto Alegre, 2009.

ASSIS, R. L. de; ROMEIRO, A. R. Agroecologia e Agricultura Orgânica: controvérsias e tendências. Desenvolvimento e Meio Ambiente, Curitiba, v. 6, p. 67-80, 2002.

BATALHA, M. O.; SOUZA FILHO, H. M. de (Org). Gestão integrada da agricultura familiar. São Carlos: Editora da Universidade Federal de São Carlos, 2005.

BARTH, M. et al. Agricultura Familiar: características ergonômicas das atividades e impactos na saúde dos trabalhadores. Estudo Sociedade e Agricultura, Rio de Janeiro v. 24, n.2, p. 471-496, 2016.

BLACKWELL, R. D.; MINIARD, P.; W.; ENGEL, J. F. Comportamento do consumidor. São Paulo: Thomson Learning, 2005. 
BRASIL. Lei n. 11.326 de 24 de julho de 2006. Estabelece as diretrizes para a formulação da Política Nacional da Agricultura Familiar e Empreendimentos Familiares Rurais. Diário Oficial da União. Brasília, DF, 25 jul. 2006. Disponível em . http://www.planalto.gov.br/ccivil_03/_ato2004-2006/2006/lei/111326.htm . Acesso em: 29 mai.2018.

BRASIL. Lei n. 10.831 de 23 de dezembro de 2003.Dispõe sobre a agricultura orgânica e dá outras providencias. Diário Oficial da União. Brasília, DF, 24 de dezembro de. 2003. Disponível http://www.planalto.gov.br/ccivil_03/Leis/2003/L10.831.htm . Acesso em: 29 mai.2018.

BRUMER, A. Gênero e agricultura: a situação da mulher na agricultura. Revista Estudos Feministas, Florianópolis, v. 12, n. 1, p. 205-227, jan. /abr. 2004.

BUAINAIN, A. M. et al. Peculiaridades regionais da agricultura familiar brasileira. In: SOUZA FILHO, H. M.; BATALHA, M. O. (Orgs.). Gestão integrada da agricultura familiar. São Carlos, SP: Edufscar, 2005.

CAMARGO FILHO, W. P. et al. Algumas considerações sobre a construção da cadeia de produtos orgânicos. Revista Informações Econômicas. São Paulo, v. 34, n.2, p. 55-68, 2004.

CAMPANHOLA, C.; VALARINI, P. J. A agricultura orgânica e seu potencial para o pequeno agricultor. Cadernos de Ciência e Tecnologia. Brasília. v. 18, n.03, p. 69-101, 2001.

CARMO, M. S. do. A produção familiar como lócus ideal da agricultura sustentável. Agricultura em São Paulo, São Paulo, v. 45, n. 1, p. 1-15, 1998.

COLLIS, J.; HUSSEY, R. Pesquisa em Administração. 2 ed. São Paulo: Bookman, 2005.

CHIA, E. et al. Comprender, dialogar, coproducir: reflexiones sobre el asesoramiento en el sector agropecuario. Agrociência, Montevideo, v. 7, n. 1, p. 77-91, 2003.

DALCIN, D. O processo de tomada de decisão em agricultores de Boa Vista das MissõesRS. 2010. 125 fls. Dissertação (mestrado em extensão rural) Programa de Pós-Graduação em Extensão Rural. Universidade Federal de Santa Maria, Santa Maria, 2010.

DAROLT, M. R. Agricultura orgânica: inventando o futuro. Londrina, PR: IAPAR, 2002.

DENT, J. B.; EDWARDS-JONES, G.; MCGREGOR, M. J. Simulation of ecological, social and economic factors in agricultural systems. Agricultural Systems, Great Britain, v. 49, n. 4, p. 337-351, 1995.

DUTRA, A. S. O. Processo Decisório de Implantação de Estrutura para Armazenagem de Soja ao Nível de Propriedade Rural na Região de Santo Ângelo/RS. 2008. 118 fls. Dissertação (mestrado em Agronegócios) Programa de Pós-Graduação em Agronegócios. Universidade Federal do Rio Grande do Sul, Porto Alegre, 2008.

FAO - FOOD AND AGRICULTURE ORGANIZATION OF THE UNITED NATIONS. Perspectivas da Agricultura e do Desenvolvimento Rural nas Américas 2014: um olhar 
para a América Latina e o Caribe. 2013. Disponível em: <

http://repiica.iica.int/docs/b3165e/b3165e.pdf>. Acesso em: nov. 2013.

FERNANDES FILHO, J. F.; CAMPOS, F. R. A indústria rural no Brasil. Revista de Economia e Sociologia Rural, Rio de Janeiro, v. 41, n. 3, 2003.

GASSON, R. Goals and values of Farmers. Journal of Agricultural and Resource Economics, Bozeman, v. 24, p. 521-537, 1973.

GLIESSMAN, S. R. Agroecologia: processos ecológicos em agricultura sustentável. Porto Alegre: Editora da UFRGS, 2005. 653 p.

GUILHOTO, J. et al. A importância da agricultura familiar no Brasil e em seus Estados. Brasília, DF: Nead, 2007.

GRAZIANO DA SILVA, J. O novo rural brasileiro. Campinas, SP: UNICAMP/IE, 2002.

IBGE- INSTITUTO BRASILEIRO DE GEOGRAFIA E ESTATISTÍCAS. O censo agropecuário 2006: agricultura familiar primeiros resultados, Brasil grandes regiões e unidades da Federação. Rio de Janeiro, p.1-267, 2006.

IFOAM- INTERNATIONAL FEDERATION OF ORGANIC AGRICULTURE MOVEMENTS. The ifoam norms for organic production and processing version 2014. Disponível em:

https://www.ifoam.bio/sites/default/files/ifoam_norms_version_july_2014.pdf. Acesso em: 29 mai. 2018.

JOHNSON, B. R.; ONWUEGBUZIE, A. J.; TURNER L. A. Mixed methods research. Journal of Mixed Methods Research, Thousand Oaks, v. 1, n. 2, p. 112-133, 2007.

KESHAVARZ, M.; KARAMI B. Farmers' decision-making process under drought. Journal of Arid Environments, London, v.108, p. 43-56, 2014.

KELLON, D; ARVAI. J. Five propositions for improving decision making about the environment in developing communities: Insights from the decision sciences. Journal of Environmental Management, London, v. 92, n. 3, p. 363-371,2011. Disponível em: <http://www.sciencedirect.com/science/article/pii/>. Acesso 10 jul 2014.

LIMA, O. O. Gestão de riscos na Agricultura Orgânica. IN: Simpósio Internacional em Gestão Ambiental e Saúde, SENAC, Santo Amaro, SP, 2005. Disponível em: http://www.planetaorganico.com.br/art.odair.htm. Acesso: 20 de mai. 2014.

LOBLEY, M. Succession in the family farm business. Journal of Farm Management, London, v.13, n. 12, 2010.

LOMOTT, M. J. LYSKAWA. K. The new instruments of risk manag ement in agriculture in the European Union. Procedia Economics and Finance, Amsterdam, v. 9, p. 321-330, 2014. Disponível em: < www.sciencedirect.com>. Acesso em: jul 2014. 
MACHADO, J. A. D. Análisis del sistema información-decisión en agricultores de regadio del Valle Medio del Guadalquivir. 1999. 307 fls. Tese (Doutorado em Economia Agroalimentar) - Universidade de Córdoba, Córdoba, 1999.

MAZZOLENI, E. M.; OLIVEIRA, L. G. Inovação tecnológica na agricultura orgânica: estudo de caso da certificação do processamento pós-colheita. Revista de Economia e Sociologia Rural. Piracicaba, SP, v. 48, n. 3, p. 567-586, 2010.

MAZZOLENI, E. M.; NOGUEIRA, J. M. Agricultura orgânica: características básicas do seu produtor. Revista de Economia e Sociologia Rural [online], v.44, n.2, p.263-293, 2006.

MZOUGHI N. Do organic farmers feel happier than conventional ones? An exploratory analysis. Ecological Economics, Amsterdam, v. 103, p. 38-43, 2014.

NELSON, A. G. Teaching agricultural producers to consider risk in decision making. Department of Agricultural Economics, Texas A\&M University. Faculty Paper Series, p. 9717. 1997.

OLIVEIRA, L. M.de. A informação como instrumeto para tomada de decisão do agricultor de Giruá no estado do Rio Grande do Sul - Brasil. 2007. 113 fls. Dissertação (mestrado em Agronegócios) Programa de Pós-Graduação em Agronegócios. Universidade Federal do Rio Grande do Sul, Porto Alegre, 2007.

ONDERSTEIJN, C. J. M.; GIESEN, G. W. J.; HUIRNE, R. B. M. Identification of farmer characteristics and farm strategies explaining changes in environmental management and environmental and economic performance of dairy farms. Agricultural Systems, Great Britain, v. 78, n. 1, p. 31-55, 2003.

PETRELLI, C. V.; SILVA, F. O novo desenho do financiamento agrícola e as dificuldades para os produtores não integrados. Anais... XVII Congresso da SOBER. SOBER. Jul./2004. Cuiabá-MT.

REICHERT, L. J.; GOMES, M. C. O processo administrativo e a tomada de decisão de agricultores familiares em transição agroecológica. Revista de la Facultad de Agronomía, La Plata, v. 112, n. 2, p. 105-113, 2013.

ROZMAM, N. et al. The dynamic simulation of organic farming development scenarios $-\mathrm{A}$ case study in Slovenia. Computers and Electronics in Agriculture, New York, v. 96, p. 163$172,2013$.

SIMON, H.A. A Behavioral Model of Rational Choice. The Quarterly Journal of Economics, Cambridge, v. 69, n. p. 99-118, 1955.

SIMON, H. A. Models of man: social and rational. New York: John Wiley \& Sons, 1957.

SIMON, H. A. Comportamento administrativo: estudo dos processos decisórios nas organizações administrativas. 2.ed. Rio de Janeiro: Fundação Getúlio Vargas, 1965.

SINGHA, C.; DORWARD, P. OSBAHR, H. Developing a holistic approach to the analysis of 
farmer decision-making: Implications for adaptation policy and practice in developing countries. Land Use Policy, Amsterdam, v. 59, p. 329-343, 2016.

SOUZA, J. L.; GARCIA, R. D. C. Custos e rentabilidades na produção de hortaliças orgânicas e convencionais no estado do Espírito Santo. Revista Brasileira de Agropecuária Sustentável (RBAS), Viçosa, v.3, n.1, p.11-24, 2013.

SCHNEIDER, S. A abordagem territorial do desenvolvimento rural e suas articulações externas. Sociologias, Porto Alegre, ano 6, n.11, p. 88-125, 2004.

Recebido em: maio de 2018 Aprovado em: setembro de 2018 